\title{
$t^{4}$ Workshop Report*
}

\section{Critical Evaluation of the Use of Dogs in Biomedical Research and Testing in Europe ${ }^{\dagger}$}

Nina Hasiwa ${ }^{1}$, Jarrod Bailey ${ }^{2}$, Peter Clausing ${ }^{3}$, Mardas Daneshian ${ }^{1}$, Marianne Eileraas ${ }^{4}$, Sándor Farkas ${ }^{5}$, István Gyertyán ${ }^{5}$, Robert Hubrecht ${ }^{6}$, Werner Kobel ${ }^{7}$, Goran Krummenacher $^{8}$, Marcel Leist ${ }^{1,9}$, Hannes Lohi ${ }^{10}$, Ádám Miklósi ${ }^{2}$, Frauke Ohl ${ }^{12}$, Klaus Olejniczak ${ }^{13}$, Georg Schmitt ${ }^{14}$, Patrick Sinnett-Smith ${ }^{15}$, David Smith ${ }^{16}$, Kristina Wagner ${ }^{17}$, James D. Yager ${ }^{18}$, Joanne Zurlo ${ }^{18}$, and Thomas Hartung ${ }^{1,18}$

${ }^{1}$ CAAT-Europe (Centre for Alternatives to Animal Testing, Europe), University of Konstanz, Germany; ${ }^{2}$ FRAME (Fund for the Replacement of Animals in Medical Experiments) \& BUAV (British Union for the Abolition of Vivisection), UK; ${ }^{3}$ AAALAC International (Association for Assessment and Accreditation of Laboratory Animal Care International); ${ }^{4}$ RTC (Research Toxicology Centre), Rome, Italy; ${ }^{5}$ Gedeon Richter Ltd, Budapest, Hungary; ${ }^{6}$ UFAW (Universities Federation for Animal Welfare, UK; ${ }^{7}$ ToxAdvice GmbH, Reinach BL, Switzerland; ${ }^{8}$ Doerenkamp-Zbinden Foundation, Switzerland; ${ }^{9}$ In vitro toxicology and biomedicine, University of Konstanz; ${ }^{10}$ University of Helsinki, Finland; ${ }^{11}$ Eötvös University, Budapest, Hungary; ${ }^{12}$ University Utrecht, Netherlands; ${ }^{13}$ Regulatory Toxicology Consultant, Berlin, Germany; ${ }^{14}$ F. Hoffmann-La Roche Ltd, Basel, Switzerland; ${ }^{15}$ Pfizer Worldwide R\&D, United Kingdom; ${ }^{16}$ EFPIA (European Federation of Pharmaceutical Industries and Associations), Brussels, Belgium; ${ }^{17}$ German Animal Welfare Federation, Munich, Germany; ${ }^{18}$ Johns Hopkins Bloomberg School of Public Health, CAAT-US, Baltimore, USA

\begin{abstract}
Summary
Dogs are sometimes referred to as "man's best friend" and with the increase in urbanization and lifestyle changes, dogs are seen by their owners as family members. Society expresses specific concerns about the experimental use of dogs, as they are sometimes perceived to have a special status for humans. This may appear somewhat conflicting with the idea that the intrinsic value of all animals is the same, and that also several other animal species are used in biomedical research and toxicology. This aspect and many others are discussed in an introductory chapter dealing with ethical considerations on the use of dogs as laboratory animals. The report gives an overview on the use of dogs in biomedical research, safety assessment and the drug developmental process and reflects the discussion on the use of dogs as second (non-rodent)species in toxicity testing. Approximately 20,000 dogs are used in scientific procedures in Europe every year, and their distinct genetic, physiological and behavioral characteristics may support their use as models for e.g. behavioral analysis and genetic research. Advances in the 3Rs (Replacement, Reduction and Refinement of experiments using dogs) are described, potential opportunities are discussed and recommendations for further progress in this area are made.
\end{abstract}

Keywords: dog use, animal welfare, moral dilemma, second species paradigm, 3Rs

\section{Introduction}

The workshop on "Critical Evaluation of the Use of Dogs in Biomedical Research and Testing" hosted by the Centre for Alternatives to Animal Testing (CAAT-Europe) and the transatlantic think tank for toxicology $\left(\mathrm{t}^{4}\right)$ took place on June 21-23, 2011 in Budapest, Hungary, and was sponsored by the DoerenkampZbinden Foundation (DZF). Participants from industry, animal welfare organizations, the regulatory arena and academia came together to discuss the current use of dogs, the regulatory background, ethical issues, and opportunities to replace, reduce and refine the use of dogs in biomedical research and testing. This report reflects the presentations given by the participants, some background information, and the discussions and recommendations of the workshop. It is not a consensus report, but shows the spectrum of views. Participants took part in the workshop because of their personal background and expertise, not as representatives of their organizations.

\section{About dogs...}

Early domestication is thought to have occurred when humans captured young wolves and selectively bred those that were tame

\footnotetext{
*a report of $t^{4}$ - the transatlantic think tank for toxicology, a collaboration of the toxicolgically oriented chairs in Baltimore, Konstanz and Utrecht sponsored by the Doerenkamp-Zbinden Foundation

† This workshop was held in memory of Hildegard Doerenkamp (1920 - 2011), the philanthropic cofounder of the Doerenkamp-Zbinden Foundation.
} 
and sociable, so that human interaction played a significant role in shaping the subspecies (Miklosi, 2007). Domestic dogs have been selectively bred for various behaviors, capabilities, and physical attributes (Dewey and Bhagat, 2002). In the past the relationship between humans and dogs was often more practical and so humans provided food, shelter and social contacts, while the dog contributed by herding, protection and hunting. Pet dog populations grew significantly after World War II as urbanization increased (Derr, 2004) and in the 1950s and 1960s, dogs were still kept outside more often than today (Franklin, 2006). In many Western countries and Japan dogs are now included in families and homes (Power, 2008).

In Europe approximately 62 million households own at least one pet, and it is estimated that these include 60 million cats and 56 million $\operatorname{dogs}{ }^{1}$. It is well established that the companionship of a pet can enhance human physical health and psychological well-being by reducing stress and blood pressure (Podberscek, 2006). Pet owners have been shown to have better mental and physical health, making fewer visits to the doctor and being less likely to be on medication than non-owners (Headey, 1999).

Dogs are also used to help disabled people: in Europe some 13,000 guide dogs assist the blind, the deaf and people with physical disabilities. They are also trained as disaster dogs to help after earthquakes or avalanches, as police dogs, searching for missing people or for security tasks such as finding explosives and drugs ${ }^{2}$.

Pets even create their own market for food and care accessories. According to a FEDIAF (European Pet Food Industry) "Facts \& Figures" document ${ }^{3}$ the sales of pet food and other related products and services has a turnover of $€ 24$ billion with a growth rate of $2 \%$ annually.

When describing the dog's role in society it should be mentioned that there are cultural differences. For example, in some East Asian countries, including Korea, China, and Vietnam, dog meat is eaten by humans and it is estimated that 13-16 million dogs are consumed in Asia every year ${ }^{4}$ - a practice that dates back to antiquity.

\section{The animal welfare perspective}

The Sixth Report ${ }^{5}$ from the European Commission on the number of animals used for experimental and other scientific purposes in the Member States of the European Union in 2008 states that 12.2 million vertebrates were used including 21,315 dogs.

The protection of animals, as anchored in the EU Treaty of Amsterdam of 1999, and amended by the Treaty of Lisbon in 2009, is a major goal that the Union should respect: "In formulating and implementing the Union's agriculture, fisheries, transport, internal market, research and technological development and space policies, the Union and the Member States shall, since animals are sentient beings, pay full regard to the welfare requirements of animals, while respecting the legislative or administrative provisions and customs of the Member States relating in particular to religious rites, cultural traditions and regional heritage." This is also the major goal of the Directives 86/609/ EEC and 2010/63/EU (Hartung et al., 2010a) on the protection of animals used for scientific purposes, the European Convention ETS 123 and the individual Animal Welfare Acts of the EU Member States. The Community Action Plan 2006-2010 and the EU Strategy for Protection and Welfare of animals 2011-2015 to be adopted in December 2011 will further this goal ${ }^{6}$.

From an animal welfare perspective, concerns arise from the fact that animal experiments cause pain, distress and harm. Housing may restrict "natural" behavior and some animals may develop dysfunctional behaviors. Stressors can also include other issues, such as transport. Moral concerns as well are raised by the fact that in most cases the animal is euthanized at the end of a procedure, although in some cases dogs may be retired and re-homed.

Further, the discussion regarding the benefits of animal research for humans (Hartung, 2008a) still is controversial. A final goal of 3Rs developments should be to replace all animal experiments by scientifically valid human cell or other models, but where this is not possible the other principles of "Reduction" and "Refinement" should be applied. The public is particularly concerned about the use of distinct animal species, such as dogs and monkeys, and some argue that these species should be given special protection. Although some legislation, such as the UK Animals (Scientific Procedures) Act from 1986 does make such special provisions for dogs, others do not.

There is little public information available about the use of dogs; therefore, a survey was carried out by the DoerenkampZbinden foundation in six randomly chosen European countries over the period from 2004-2006 on publicly available information, taking into account the EC Report as well as online search tools like PubMed and Google Scholar. Very limited information could be retrieved, for example on the detail of experimental procedures, making it impossible for the public to assess the severity of experiments, numbers of animals used in any particular experiment and the level of pain and distress inflicted.

The number of animals used is known from public statistics, but the procedures used on the animals cannot be found in the scientific literature. Publications from the six surveyed countries, which represented roughly half of the EU animal use in research, accounted for only 800 of the approximately $20,000 \mathrm{dogs}$ used in Europe, most probably due to the following points:

- Not all papers are published in English.

- Experiments are often not published when they have not produced positive results or were aborted.

- Experiments that are performed in private laboratory facilities and/or companies, where the results are used to fulfill le-

\footnotetext{
$1 \mathrm{http}: / /$ www.ifaheurope.org/CommonTP.aspx?SubMenuld=58\&Menuld $=17$

$2 \mathrm{http}: / /$ www.ifaheurope.org/html/document.aspx?id=43\&hash=ba7621fbb5e28c3efe215a2270c08ca6

$3 \mathrm{http}: / /$ www. fediaf.org/facts-figures/

4 http://www.animalpeoplenews.org/03/9/dogs.catseatenAsia903.html

5 http://eur-lex.europa.eu/LexUriServ/LexUriServ.do?uri=COM:2010:0511:REV1:EN:PDF

$6 \mathrm{http} / / /$ ec.europa.eu/food/animal/welfare/actionplan/actionplan_en.htm
} 
gal requirements, are submitted to the respective authorities rather than being published in the peer-reviewed literature.

- Experiments published in the cited year might have been carried out long before the year of publication.

To support ethical committees and prevent duplication of procedures an easily accessible online database might be useful, where research facilities can share their data. This was considered an attractive idea by most of the workshop participants, but the practical difficulties might be huge. Most of the pharmaceutical testing is done on new compounds, so the comparison of data might be difficult. A certain degree of privacy protection might help to overcome most of the other concerns.

\section{Moral dilemma}

The current relevance of animal welfare issues is strongly based on societal concerns about how animals are treated. In order to deliver solutions to perceived welfare issues, animal welfare scientists must take both the societal perception and scientifically based considerations into account: The recommendations they make regarding animal welfare issues must comply with the moral values of society in order to generate sustainable approaches. For doing so, a systematic approach is needed to identify potential moral dilemmas in animal welfare and factors that might influence these dilemmas. The Dutch Animal Welfare Council recently developed such an approach, the so-called ethical framework ${ }^{7}$, demonstrated in Figure 1, to structure discussions about the ethical dimension of current and potential future animal welfare issues. Such a discussion should cover what needs to be done from a moral perspective in any given situation, identify relevant ethical issues (specifically in relation to animal welfare), and outline the steps that need to be taken to resolve these issues. It should be clear that such a framework is intended to identify relevant ethical issues and potential moral dilemmas rather than to yield straightforward solutions. Fur-

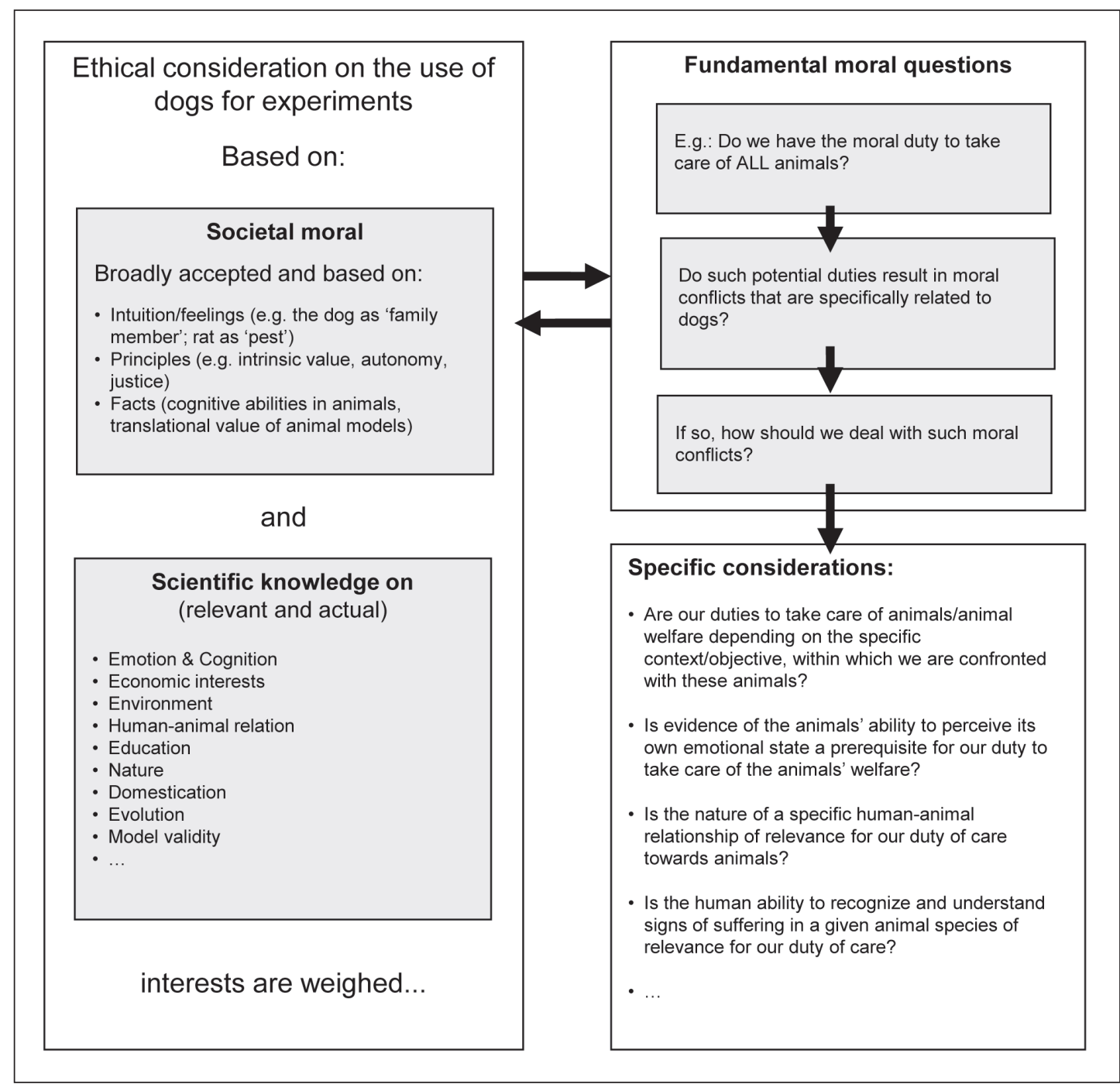

Fig. 1: Framework to structure discussions about ethics

The aim of this framework (adopted from RDA, 2010) is to structure discussions about the ethics of the use of dogs as experimental animals. Such discussions should cover what we should do from a moral perspective in a given situation, identify relevant ethical issues, and outline the steps that need to be taken to resolve this issue (kindly provided by Frauke Ohl, University of Utrecht, The Netherlands).

\footnotetext{
7 http://www.rda.nl/pages/adviezen.aspx
} 
thermore, the results of these considerations will not be universally valid but will differ significantly between societies. The importance of such a framework is that it provides a basis for discussion of animal welfare within a given society.

From the scientific point of view some people may conclude, that the dog represents an animal model of better validity for distinct research questions than other animal models, while other scientists strictly disagree. Given the presupposition that all animals have an intrinsic value, one must conclude that the choice of animal species for experimental purposes needs to be based on objective criteria such as model validity. On the other hand, an ethical justification for replacing dogs with another species may be difficult to find. However, it has to be acknowledged that the emotional value of dogs for humans does result in a moral dilemma, not only within the broader society, but often as well for humans conducting experiments.

While we therefore do not oppose the societal wish to direct special attention to the application of the $3 R$ s to the use of dogs in experimental research, we wish to emphasize that this approach may result in the use of less valid models or may require a higher number of animals to obtain reliable results.

\section{Main areas of dog use}

\subsection{In general}

Historically, the use of dogs as animal models for research and testing evolved because of their availability, size, and the ease of use. Their anatomy and physiology are similar in many aspects to those of humans. As adapted from the European Commission Staff Working Document ${ }^{8}$, which accompanied the Report on the number of animals used for experimental and other scientific purposes, and shown in Table 1, more than $50 \%$ of all dogs are used in "Toxicological and other safety evaluations of products and devices for human medicine and dentistry and for veterinary medicine". This is in contrast to overall experimental animal use, where toxicology and other safety evaluations count for $8.7 \%$ of all animals used. Nearly a quarter of all dogs are used in "Research and development of products and devices for human medicine and dentistry and for veterinary medicine", whereas "Production and quality control of products and devices for veterinary medicine", "Biological studies of a fundamental nature" and "Diagnosis of disease" comprise the last quarter of total dog use.

Our report will focus mainly on toxicological and other safety evaluations, biomedical research, and the development of products, but will mention also some examples of dog use which might not be that prominent, e.g., the dog as a genetic model. While most genetic work is carried out in mice, there are 220 homologous hereditary diseases with uniform genetic mutations shared by $\operatorname{dog} s$ and humans, where research on dogs is thought by some scientists to give deep insight, knowledge, and understanding of disease mechanisms and possible cures, e.g., bleeding disorders (haemophilia A and B), leukocyte adhesion deficiency, retinal degeneration (retinitis pigmentosum) and narcolepsy, while other scientists disagree.

\subsection{The two-species paradigm}

In 1965 the US FDA (Food and Drug Administration) introduced the two-species paradigm, by which non-rodent species are required to provide sufficient data to pick up drug effects not observed in the rodent species. The second-species paradigm is still applied today, is mandatory in many cases, such as in the guidance of FDA, CHMP (Committee for Medicinal Products for Human Use), ICH (International Conference on Harmonization), and the OECD (Organization for Economic Co-operation and Development). Pharmaceutical and agrochemical companies are presented with limited alternatives and commonly the

\section{Tab. 1: Areas of dog use}

Adapted from the Table "Number of animals used in experiments for selected purposes data of 2008 in Europe 27*" from the European Commission Staff Working Paper - Accompanying document to the Report from the Commission to the Council and the European Parliament on animal numbers used for scientific purposes

\begin{tabular}{|l|r|}
\hline Biological studies of a fundamental nature & $\mathbf{1 8 4 1}$ \\
\hline $\begin{array}{l}\text { Research and development of products and devices for human medicine and dentistry and for veterinary medicine } \\
\text { (excluding toxicological and other safety evaluations) }\end{array}$ & $\mathbf{4 4 0 5}$ \\
\hline Production and quality control of products and devices for human medicine and dentistry & $\mathbf{2 0 7 0}$ \\
\hline Production and quality control of products and devices for veterinary medicine & $\mathbf{1 1 0 7 7}$ \\
\hline $\begin{array}{l}\text { Toxicological and other safety evaluations (including safety evaluation of products and devices for human medicine } \\
\text { and dentistry and for veterinary medicine) }\end{array}$ & $\mathbf{1 1 1 1}$ \\
\hline Diagnosis of disease & $\mathbf{3 6 2}$ \\
\hline Education and training & $\mathbf{3 1 6}$ \\
\hline Other & $\mathbf{2 1 3 1 2}$ \\
\hline All dogs used in 2008 & \\
\hline
\end{tabular}

*(France reporting for 2007)

As stated in the Commission staff working paper: "Other" covers a wide range of experiments such as virology, immunology for production of monoclonal and polyclonal antibodies, physiology of fetal-maternal interaction in mouse gene transgenesis, oncological treatment, pharmaceutical research and development, combined drug testing and genetics.

8 http://ec.europa.eu/environment/chemicals/lab_animals/pdf/sec_2010_1107.pdf 
Tab. 2: The dog as $2^{\text {nd }}$ species in EU legislation on chemicals, biocidal and plant protection products (Kindly provided by Kristina Wagner, German Animal Welfare Federation); emphasis added.

\begin{tabular}{|c|c|c|c|}
\hline EU legislation & Endpoint & Test method / Study & $\begin{array}{l}\text { Explicit } \\
\text { requirement of } \\
\text { use of dogs }\end{array}$ \\
\hline $\begin{array}{l}\text { REGULATION (EC) } \\
\text { No } 1907 / 2006 \text { (REACH): } \\
\text { Annex } 9 \text {, } \\
\text { information requirements } \\
\text { for substance quantities of } \\
100 \text { tonnes and more }\end{array}$ & $\begin{array}{l}\text { 8.7. Reproductive } \\
\text { Toxicity }\end{array}$ & $\begin{array}{l}\text { 8.7.2. Pre-natal developmental toxicity study, one } \\
\text { species, [...] (B.31 of the Commission Regulation on test } \\
\text { methods as specified in Article 13(3) or OECD 414). } \\
\text { Specific rules for adaption from standard information required } \\
\text { [...] A decision on the need to perform a study at this tonnage } \\
\text { level or the next on a second species should } \\
\text { be based on the outcome of the first test and all other relevant } \\
\text { available data. }\end{array}$ & NO \\
\hline $\begin{array}{l}\text { REGULATION (EC) } \\
\text { No } 1907 / 2006 \text { (REACH): } \\
\text { Annex } 9 \text {, } \\
\text { information requirements } \\
\text { for substance quantities of } \\
100 \text { tonnes and more }\end{array}$ & $\begin{array}{l}\text { 8.7. Reproductive } \\
\text { Toxicity }\end{array}$ & $\begin{array}{l}\text { 8.7.3. Two-generation reproductive toxicity, one species, male } \\
\text { and female, [...] } \\
\text { Specific rules for adaption from standard information required } \\
\text { [...] A decision on the need to perform a study at this tonnage } \\
\text { level or the next on a second species should be based on the } \\
\text { outcome of the first test and all other relevant available date. }\end{array}$ & NO \\
\hline $\begin{array}{l}\text { Proposal for a REGULATION } \\
\text { OF THE EUROPEAN } \\
\text { PARLIAMENT AND OF THE } \\
\text { COUNCIL concerning the } \\
\text { placing on the market and use } \\
\text { of biocidal products, (Political } \\
\text { agreement reached in Council; } \\
2009 / 0076 \text { (COD)) } \\
\text { Annex II, Active Substances, } \\
\text { Title 1, Chemicals }\end{array}$ & $\begin{array}{l}\text { 8.9. Repeated } \\
\text { dose toxicity }\end{array}$ & $\begin{array}{l}\text { 8.9.4. Further repeat dose studies } \\
\text { ADS [ADS=additional data set] } \\
\text { "Further repeat dose studies including testing on } \\
\text { a second species (non-rodent), [...] }\end{array}$ & NO \\
\hline \multirow[t]{3}{*}{$\begin{array}{l}\text { Regulation EC } 440 / 2008 \\
\text { (Commission Regulation on } \\
\text { test methods), } \\
\text { Annex B. }\end{array}$} & $\begin{array}{l}\text { B.27. Sub-chronic } \\
\text { oral toxicity } \\
\text { repeated dose in } \\
\text { non-rodents }(90 \mathrm{~d})\end{array}$ & $\begin{array}{l}\text { "The commonly used non-rodent species is the dog, [...]" } \\
\text { (This sub-chronic oral toxicity test method is a replicate of } \\
\text { OECD TG 409) }\end{array}$ & YES \\
\hline & $\begin{array}{l}\text { B.3. Acute toxicity } \\
\text { (dermal) }\end{array}$ & $\begin{array}{l}{[\ldots] \text { The adult rat or rabbit may be used. }[\ldots]} \\
\text { Other species may be used but their use would require } \\
\text { justification. } \\
{[\ldots] \text { Note: in acute toxicity tests with animals of a higher }} \\
\text { order than rodents, the use of smaller numbers should } \\
\text { be considered. [...] }\end{array}$ & NO \\
\hline & $\begin{array}{l}\text { B.30. Chronic } \\
\text { toxicity test }\end{array}$ & $\begin{array}{l}{[\ldots] \text { The preferred species is the rat. }} \\
\text { Based upon the results of previously conducted studies } \\
\text { other species (rodent or non-rodent) may be used. [...] } \\
{[\ldots] \text { For non-rodents a smaller number of animals, but at }} \\
\text { least four per sex per group, is acceptable. [...] }\end{array}$ & NO \\
\hline $\begin{array}{l}\text { OECD Test Guidelines for the } \\
\text { testing on chemicals }\end{array}$ & $\begin{array}{l}\text { TG } 409 \\
\text { Repeated Dose } \\
\text { 90-Day Oral } \\
\text { Toxicity Study in } \\
\text { Non-Rodents }\end{array}$ & "The commonly used non-rodent species is the dog, [...]" & YES \\
\hline \multirow{3}{*}{$\begin{array}{l}\text { Draft Regulation laying } \\
\text { down test methods / Data } \\
\text { requirements for Active } \\
\text { Substances in Plant } \\
\text { Protection Products (SANCO } \\
11802 / 2010 \text { ), } \\
\text { ANNEX II, } \\
\text { Part A, } \\
\text { Chemical active substances }\end{array}$} & \multirow[t]{3}{*}{$\begin{array}{l}\text { 5.3. Short-term } \\
\text { toxicity }\end{array}$} & $\begin{array}{l}\text { 5.3.2. Oral } 90 \text {-day study } \\
{[\ldots] \text { The short-term oral toxicity of the active substance to }} \\
\text { rodents ( } 90 \text {-day), usually the rat, a different rodent species } \\
\text { shall be justified, and non rodents ( } 90 \text {-day toxicity study } \\
\text { in dogs), shall always be reported. [...] }\end{array}$ & YES \\
\hline & & $\begin{array}{l}\text { 5.5. Long term toxicity and carcinogenicity } \\
{[\ldots] \text { If comparative metabolism data indicate that either rat }} \\
\text { or mouse is an inappropriate model for human cancer risk } \\
\text { assessment, an alternative species could be considered if } \\
\text { justified. }\end{array}$ & NO \\
\hline & & $\begin{array}{l}\text { 5.8.2. Supplementary studies on the active substance } \\
{[\ldots] \text { a) studies on absorption, distribution, excretion and }} \\
\text { metabolism, in a second species, [...] }\end{array}$ & NO \\
\hline
\end{tabular}


dog is used as the second non-rodent species. In Table 2 the "German Animal Welfare Federation" summarized EU legislation on chemicals, biocidal products and plant protection products that requires a second species, with special emphasis on the requirement of the dog.

\subsection{Regulatory toxicology}

\section{Pharmaceuticals}

An Industry/Welfare Steering Group (Smith et al., 2002) reviewed the areas where dogs are used. Safety pharmacology includes studies performed during the early development of a drug, before a first clinical trial. These studies may use dog tissue and organs for in vitro cardiovascular assessment. Non-recovery studies involving anesthetized dogs may be performed to assess hemodynamics, cardiovascular parameters, respiratory and renal functions. The less invasive model uses telemetered, conscious dogs to assess the cardiovascular system, thereby satisfying the regulatory demand of the safety pharmacology core battery.

Cardiovascular side effects have been among the most frequent causes for drug withdrawals, which eventually led to the first international regulatory guideline on safety pharmacology (ICH S7A $)^{9}$ in 2000 to ensure the safety of human volunteers and patients participating in an early phase of clinical trials. Though safety pharmacology testing was done before the guideline, a global harmonization component was added by its implementation. The "Safety Pharmacology Core Battery" was developed to assess drug effects on the functions of critical organ systems, e.g., cardiovascular, central nervous and respiratory function. In 2005 "The Nonclinical Evaluation of the Potential for Delayed Ventricular Repolarization (QT Interval Prolongation) by $\mathrm{Hu}-$ man Pharmaceuticals" (ICH S7B) was introduced. Both guidance documents anticipated dog use with different emphasis of the role of in vitro and in vivo studies.

Dog studies are performed with single or multiple doses (fixed or ascending) to determine dose selection and to assess target organ toxicity, Maximum Tolerated Dose and Dose Range Finding (MTD/DRF). Often the study starts with an ascending dose in few animals until first signs of toxicity occur, is continued with a EIH (Enter Into Humans) GLP (Good Laboratory Practice) study requiring a sufficient number of animals to assess target organ toxicity and reversibility, determine the safe starting dose, derive safety margins and set the ceiling exposure to support clinical planning, and ends with a long-term GLP study with a statistically valid number of animals to support long-term clinical studies and marketing. Repeat Dose is the pivotal study in a regulatory package in pharmaceutical development and durations of 14 days to 1 month, 3 months, and 9 to 12 months are generally used. In some cases, some of these studies may be omitted depending on the clinical program (duration of human studies) or the therapeutic indication (6 months studies are sufficient for some countries or indications). Study designs are generally well defined and include extensive in-life monitoring, e.g., ECG (electrocardiography), hematology, clinical chemistry, ophthalmology and detailed histopathology.
Changes in regulatory toxicology testing were often driven by tragedies (e.g., thalidomide; Kim and Scialli, 2011), and the liability of producers for their product, and the safety of volunteers and patients for the drug under investigation created the need for testing. Every new incidence has added another patch of safety measures and guidelines, some of them dating back to the 1960s and earlier, based on the belief that more in vivo testing would solve the problem, but often largely unmodified with difficulties to adapt to new scientific advances (Hartung, 2009a, 2011). Testing should take place not as a default but on a need-to-know basis and there are cases where this paradigm is applied. An example is the guideline ICH S9, which regulates anti-cancer drugs for patients at the terminal stage, and neither long-term toxicity studies, nor fertility or pre- and post-natal studies are generally required. Therefore, the need to perform studies on non-rodent species is limited here, and they are basically used for short-term studies and embryo-fetal development, mainly carried out in rabbit or monkey.

\section{Chemicals}

In chemical development, studies with repeated dosing up to 13 weeks are usually sufficient for filing. In some territories, e.g., Japan and Brazil, regulatory authorities still expect data covering 6 months, which means that these studies are still conducted, even though they are considered unnecessary by the US and EU.

\section{Juvenile studies}

Toxicity studies for drugs intended for use in children and adolescents represent another potential requirement of regulators to allow clinical pediatric drug development. The safety and efficacy for children and adolescents has not been studied in animals systematically until recently and the default conclusion was that a new drug is not recommended for use in children and adolescents due to lack of data. The design of these studies is often similar to those of repeat dose studies but using very young animals. The species is not explicitly prescribed, but the choice should be appropriate for evaluating toxicity endpoints relevant to the intended pediatric population and both sexes are obligatory. Standard non-clinical studies using adult animals, or safety information from adult humans, cannot always adequately predict these differences in safety profiles for all pediatric age groups, especially effects on immature systems that undergo postnatal development, such as the brain, the pulmonary system, the kidneys, the reproductive system, the immune system, the skeletal system and even other organs or tissues which may play a critical role in the pharmacokinetics of a medicinal product ${ }^{10}$. This point has to be taken into special consideration, because it might lead to new testing requirements for other distinct populations in addition to juveniles, e.g., the elderly, and diabetic or immune-compromised patients.

\section{Pesticides}

For pesticide testing, one rodent and one non-rodent species are required. Dogs are used as non-rodent species for oral subchron-

9 http://www.ich.org/fileadmin/Public_Web_Site/ICH_Products/Guidelines/Safety/S7A/Step4/S7A_Guideline.pdf

$10 \mathrm{http}: / /$ www.ema.europa.eu/docs/en_GB/document_library/Scientific_guideline/2009/09/WC500003305.pdf 
ic and chronic toxicology studies. In many cases, the dog appears to be more sensitive than the rat, i.e., they show effects at lower doses. Notably, new regulations have been adopted in the US that eliminate the one-year chronic toxicity study in the non-rodent; the subchronic 90 day study is considered sufficient because meta-analysis showed that there is no significant additional information obtained from a longer study (Kobel et al., 2010). EU regulations are also changing to allow a 90 day study without the need for a one year study, but unfortunately Japan and Brazil still require the one year test. Thus, a European or US company intending to sell to the Japanese or Brazilian market must still perform a one-year study in the non-rodent, i.e., dog.

\section{Non-pharmaceuticals}

For some non-pharmaceutical products, e.g., agrochemicals and biocides, it is explicitly indicated that the dog is the first choice as a non-rodent species for toxicity testing. This approach appears to be based on historical experience and tradition rather than scientific rationale, but is strongly supported by Guidelines. OECD 409 demands: "The commonly used non-rodent species is the dog, which should be of a defined breed" and OPPTS 870-3150 states specifically: "The commonly used non-rodent species is the dog, preferably of a defined breed; the beagle is frequently used. If other mammalian species are used, the tester should provide justification/reasoning for his or her selection."

\subsection{Other areas}

Non-clinical tests on dogs are also conducted for certain alimentary products and veterinary medicines. Dog research is also done on diseases and conditions particular to dogs, including chronic pain, hip dysplasia and behavioral diseases. Conditions in specific breeds like mast cell tumors in Labrador Retrievers, rage syndrome in English Springer Spaniels or inflammatory bowel disease in Boxers are among the numerous examples that have prompted specific studies.

\section{The selection of the second species}

Directive 2010/63/EC, Recital 13 states that "The choice of methods and the species to be used have a direct impact on both the numbers of animals used and their welfare. The methods selected should use the minimum number of animals that would provide reliable results and require the use of species with the lowest capacity to experience pain, suffering, distress or lasting harm that are optimal for extrapolation into target species."

Traditionally, the dog is considered the non-rodent species of first choice, due to the fact that Beagles are purpose-bred and easily available and knowledge on their physiology is extensive. The choice of non-rodent species in toxicological programs has to be specifically justified based on scientific evidence relating to the predictability of the animal model for the specific function. All available information, like in vitro data and state-of-the-art literature, must be taken into account to ensure the choice of the best model. Species selection must be made on a case-by-case basis, indicating scientific justification, ethical perspectives, technical considerations, and regulatory acceptability, weigh- ing the pharmacological activity of the drug, the pharmacokinetic profile allowing sufficient exposure, and analysis of the metabolism and its similarity to humans. Best scientific practice and therefore enhanced consumer safety requires using the best model, not the one that is most easily available. It always should be kept in mind that species choice needs to be specific to the compounds under investigation. That would also suggest that academia and industry should publish their findings to avoid unnecessary duplicative testing. Some examples of limitations in the use of dogs are given in Table 3.

The use of dogs as a second species in safety evaluations is closely linked to a long-lasting discussion on multiple species toxicity testing in general. Retrospective analyses of the additional value of dog studies over rodent studies have been published in the area of pesticide testing, where extensive information is available in several national registers (Gerbracht and Spielmann, 1998; 2001; Box and Spielmann, 2005; Kobel et al., 2010). Such studies indicated early on, that for instance mouse data provide no gain of knowledge, when rat and dog data are available. However, detailed analysis of chronic and subchronic toxicity studies also indicated that the dog is the more sensitive species (when compared to rats) in about $15 \%$ of all cases. Thus, the dog studies contributed clearly to the definition of the NOEL (no observed effects level). Since the NOEL is used as point of departure for safety regulations, dogs were required in the field of pesticides according to these retrospective surveys of several hundred compounds (Box and Spielmann, 2005; Kobel et al., 2010). However, more detailed analysis also examined the need for long-term (12 month) dog studies, in addition to shorter studies (90 days), and the conclusion of international regulatory experts was that dogs as second species for long term studies beyond 13 weeks are dispensable (Kobel et al., 2010; Dellarco, 2010).

Some retrospective data are also available from the field of pharmaceuticals. A study by Olson (Olson et al. 2000) compared human toxicities of about 150 drugs with the respective preclinical toxicity data obtained in rodent and non-rodent species. They used this data base to investigate the predictive value of the two-species approach. They found that a better test sensitivity was obtained when data from two species (e.g. dog and rat) were combined. Non-rodent data from either non-human primates or dogs taken together with rodent data predicted human toxicity in $71 \%$ of all cases, while rodent data only predicted $43 \%$ of human toxicities.

This study is often taken as evidence that the non-rodent species is indispensable for human safety assessment, and that inclusion of several species increases test sensitivity. However, it is also well-known that this approach invariably decreases test specificity and leads to a large number of false positive results (Hartung, 2009a). As the authors of the Olson report themselves admitted, "A more complete evaluation of the predictability aspect will be an important part of a future prospective survey." A statistician elaborated on this in 2008 (Matthews, 2008), and concluded: when the correct definitions of sensitivity, specificity and likelihood ratio are used, "the data provide no statistically credible evidence that these animal models [dogs and monkeys] contribute any predictive value, either separately or in combination." Therefore, some scientists conclude that published data 
Tab. 3: Limitations for the use of dogs with examples of oversensitivity

\begin{tabular}{|l|l|}
\hline Limitations for the use of dogs & Examples of oversensitivity \\
\hline Convulsions & dose-limiting \\
\hline Emesis* & insufficient exposure or erratic dosing \\
\hline Non-steroidal anti-inflammatory drugs & GIT lesions \\
\hline Vasodilators \& anti-hypertensives & arteriopathy \& cardiotoxicity \\
\hline Hormones & females may be very sensitive to estrogens and anti-estrogens \\
\hline Drugs causing histamine release & dose-limiting due to pseudo-allergy \\
\hline
\end{tabular}

${ }^{\star}$ Emesis is controversially discussed (du Sert et al., 2011).

to demonstrate the need for dogs in drug safety testing is lacking, and that it is possible to achieve a reduction and refinement in dog use without compromising human safety (Broadhead et al., 2000). Since both drug testing and also general biological knowledge have changed considerably during the last 10 years, new comprehensive retrospective evaluations would shed more light on the predictivity, sensitivity and specificity aspects of using dogs in safety evaluations. We suggest such studies, applying the principles of evidence-based toxicology (Hofmann and Hartung 2006; Hartung, 2009b), to provide a more solid scientific basis for future discussions on this topic.

In order to respond to public concerns toward laboratory dogs an EU FP6 Specific Support Action (SSA) project called "RETHINK" was initiated to investigate the feasibility of the minipig as an alternative model for regulatory toxicity testing. RETHINK was a multinational project, co-funded by the European Commission, consisting of 5 Working Groups, where several invited experts from the European Union reviewed the impact of toxicity testing in mini-pigs over the period 2006-2008 including an evaluation of the potential 3 Rs contribution. The results were published in 2010 in a special issue of the Journal of Pharmacological and Toxicological Methods (Forster et al., 2010).

Over the last ten years there has been a reduction of the use of dogs and a concurrent increased interest and acceptance of minipigs as an alternative non-rodent species in accordance with the RETHINK conclusions. They recognized areas where a case-bycase analysis will favor the use of the mini-pigs over the dog in toxicology and drug development. The workshop participants agreed that replacing one sentient being by another equally sentient one cannot be called a 3Rs initiative, and should not be the final goal.

An EFPIA document of species selection is currently in preparation and builds on the "Points to Consider" document published jointly in 2002 in the UK by the ABPI (Association of British Pharmaceutical Industry) and the Home Office ${ }^{11}$.

\section{The dog as a new "natural model" for human behavior}

As already mentioned, humans and dogs have coexisted in close proximity for a long time, sharing the same nutrition, life

11 http://www.abpi.org.uk/our-work/library/guidelines/Pages/non-rodent.aspx

12 http://www.eurolupa.org/ style and living environment. Certainly dogs have influenced humans but humans have influenced dogs much more by selective breeding, therefore enhancing certain phenotypes. Studies are ongoing in canine science, cognitive ethology, dog-human communication as well as the dog-wolf comparison (Gácsi et al., 2005) exploring the dog as a natural model for human behavior (Miklósi, 2007). Dogs may help to trace human behavioral evolution by evaluating human species-specific behavioral traits that possibly evolved after the "pan" and "homo" split (approx. 6 million years ago) with those of the dogs having evolved around 15-25,000 BC. This convergence in dog social behavior led to a nearly symbiotic relationship between these two species. The natural environment for a dog is the one offered by a human being.

This idea led to studies in which an association of a polymorphism in the dopamine D4 receptor gene and the (hyper-) activity of dogs was discovered (Hejjas et al., 2007), which in turn led to observations regarding human ADHD (attention deficit hyperactivity disorder). Furthermore, a potential cure may have been identified, as indicated by the discovery that dietary supplementation with medium-chain triglycerides resulted in long-lasting cognition-enhancing effects in aged dogs (Pan et al., 2010).

For some scientists dogs may provide a good "natural model" for studying behavior, while others disagree. Nevertheless, if these studies are conducted, emphasis has to be put on the methods used to measure the behavioral phenotype. These methods should lead to the development of ecologically and socially valid tests, and the introduction of non-invasive testing methods that are the basis for a sound analysis. These kinds of studies may be helpful to develop tools to determine and measure animal welfare, which would be a prerequisite to further improvement in the area of refinement.

\section{Canine models of human inherited disorders}

Dogs are being used in attempts to further understand and elucidate human diseases and contributions of about $€ 12$ million are given by the EU for canine disease genetics ${ }^{12}$, acknowledging the potential value for human health. Some people may assume that dogs are clinically and physiologically closer to humans 
than tiny rodents and that human and canine diseases progress more similarly, others may disagree.

The various dog breeds carry unique breed-specific variations in morphological and behavioral traits and more than 600 genetic disorders are described with around $70 \%$ of the diseases having corresponding human conditions. Dogs have the advantages of a large pedigree and a unique population history of around 9000 generations with a unique breed structure of more than 400 genetic isolates (Karlsson and Lindblad-Toh, 2008).

These characteristics may lead, for some scientists, to the conclusion that the dog might be a natural model for human disorders like epilepsy, separation anxiety, obsessive-compulsive behavior, and aggression. A large dog DNA bank has already been established where several new loci and genes have been identified for different diseases, most of them as new candidates for corresponding human disorders. The process is non-invasive and requires only the dog owner's consent, a blood sample and a phenotype characterization by completion of a questionnaire.

This knowledge opens a new area of discussion on the use of dogs. One option might be to simply exclude animals with genetic defects from breeding, but this may raise new ethical issues, because pharmaceutical companies and biomedical research scientists might consider using these animals under purpose-bred conditions to find and develop new drugs.

\section{Replacement}

Replacement, as introduced by Russell and Burch as a part of the 3Rs principle for humane experimental technique in 1959 (Russell and Burch, 1959), refers to methods that avoid or replace the use of animals, where they would otherwise have been used. Replacement methods can be absolute replacements techniques that do not involve live animals at any point, such as computer modeling, cell culture and tissue engineering or other in vitro methodologies - or relative replacements, which replace the use of (higher) animals by non-sentient species ${ }^{13}$. In Recital 10, European Directive 2010/63/EU clearly identifies full Replacement procedures on live animals for scientific and educational purposes as the final goal, "as soon as it is scientifically possible to do so." Furthermore, the Directive states in its Article 4, Part 1: "Member States shall ensure that, wherever possible, a scientifically satisfactory method or testing strategy, not entailing the use of live animals, shall be used instead of a procedure."

Unfortunately, there are no methods or strategies available at the moment to ensure a full Replacement of experiments on dogs, so the main research effort and funding should be directed towards the development of such methods. Scientific and technical progress are moving fast and new and promising methods are being developed constantly, so it will be a question of identifying or promoting those that are suitable to address scientific questions and satisfy the needs for more humane and evidence-based safety testing. These methods and techniques also will need to be internationally accepted and to be integrated in testing strategies.
Tox-21c (NRC, 2007; Krewski et al., 2010), i.e., the vision put forward by the 2007 publication of the US National Research Council "Toxicity Testing in the $21^{\text {st }}$ Century: A Vision and a Strategy", offers a completely new way of approaching toxicology by identifying pathways of toxicity (Hartung and McBride, 2011, Andersen et al., 2011), looking at modes of action, and developing in vitro tests which are directly guided to the mechanism of toxicity instead of the "black box approach" the animal provides. Though this vision has no aspect specific to dog use, it has created a spirit of optimism that the replacement of currently conducted animal testing by mechanistically based higher throughput tests can be possible (Hartung, 2008a; 2010b; Hartung and Koëter, 2008; Hartung and Leist, 2008), using human cells (Leist et al., 2008; Kuegler et al., 2010), response pathways (Alon, 2007), and evidence-based procedures (Hoffmann and Hartung, 2006; Hartung, 2009b) to develop scientifically sound "Integrated Testing Strategies" (Jaworska and Hoffmann, 2010).

There are ongoing efforts in which experts from animal welfare organizations work together with regulators to produce new drug development guidelines for the use of alternative methods to replace animal use.

\section{Reduction}

The approach to the reduction of dog use was addressed by a UK "Industry/Animal Welfare Initiative to minimize dog use in preclinical toxicology" following a workshop on "The dog in regulatory toxicology" (Smith et al., 2002). A Consortium of European pharmaceutical companies, including the Fund for the Replacement of Animals in Medical Experiments (FRAME) and the Royal Society for the Prevention of Cruelty to Animals (RSCPA), was formed, supported by the European Federation of Pharmaceutical Industries (EFPIA) and the Association of the British Pharmaceutical Industry (ABPI).

The project was divided into three phases covering (1) Best practice in study design (Refinement/Reduction/Replacement), (2) Industrial co-operation and data sharing (Reduction), and (3) Assessing the need for particular studies (Replacement).

In phase 1 (Best practice in study design) different approaches were investigated:

- Design of preliminary studies

- Group sizes for repeat-dose studies

- Use of single sex studies

- The need for recovery groups

- The use of control animals

- Overall program design

Preliminary studies are usually conducted outside of the regulatory framework because they are used to collect information for future studies, particularly dose range finding and the maximum tolerated dose. Through analysis of an industry questionnaire the group found that there was no consensus on design or power of the studies conducted. Furthermore, in 12 responding companies, 15 different study designs were used with variations in many design aspects and in numbers of dogs. The results opened

\footnotetext{
13 http://www.nc3rs.org.uk/page.asp?id=7
} 
the opportunity to develop a harmonized design by reviewing the intended purpose of the study with regard to numbers of animals and outcome of the 14- or 28-day study. The primary purpose is dose selection (high dose) for the pivotal repeat dose study and the secondary purpose is the detection of serious toxicity. In this way candidate drug selection can be confirmed and an estimation of compound requirements and toxicokinetic data can be obtained. Thus, a preliminary prediction of dose levels for 14- or 28-day studies can be made based on a low number of animals used (9-12 animals showed best results). After a thorough review, harmonization of the principal study design was proposed, which led to a reduction in dog use by applying the optimized design and endpoints (Smith et al., 2005)

Phase 2 consisted of a data-sharing initiative to avoid unnecessary duplication of studies within pesticide, chemical and pharmaceutical sectors. The authors also supported the development of a central database of animal experiments, including a vehicle database containing in vivo toxicological information on non-active formulation ingredients (vehicles, solvents, excipients, preservatives, etc.) and selected chemicals, in terms of its potential to share qualitative and quantitative data between interested parties. The database is hosted by Lhasa Ltd. It offers free access for collaborating companies and operates with a search fee for outsiders.

In phase 3, the assessment of the need for particular studies took place and suggestions were to eliminate the terminal 3 or 6 month study by maximizing data from safety pharmacology in 1 month studies, using interim readout from the 9 or 12 month study combined with non-destructive sampling. Unfortunately, it is necessary to wait for the outcome of biomarker/-omics projects before proceeding with this part of the project.

The impact of these best practices in MTD/DRF study design initiative was estimated to account for a reduction by $40-120$ dogs/company/year, the elimination of acute toxicity testing (for Japan) saves 8-16 dogs/company/year and standardization of group sizes for repeat dose studies resulted in small gains. A 2006 survey in the UK showed that the removal of control recovery groups might be able to save 120 dogs per year, but some companies are still concerned about the scientific and regulatory repercussions of that question (Smith et al., 2007).

\section{Refinement}

There are a number of resources already available to assist with refinement of dog care and use (Wells, 2004; Hubrecht and Kirkwood, 2010). They provide an extensive collection of recommendations on housing, physical environment, food and feeding, environmental enrichment, exercise, health and hygiene, breeding, balancing supply and demand, grouping, transport, handling and restraint, procedures, long-term use, re-homing, staff training and areas for future research to refine further dog husbandry and care (BVAAWF/FRAME/RSPCA/UFAW Joint Working Group on Refinement, 2004).

The main breed used in laboratories is the Beagle and, in Europe, animals used in experiments must be purpose-bred. To minimize the creation of surplus animals all possible meas- ures should be taken to ensure the supply of animals does not exceed demand. Dog housing should aim to meet the physical, physiological, behavioral and social needs and as a guiding principle, housing and husbandry should be managed in order to allow animals to perform a wide range of species-specific behaviors.

The dog is a social, macro-osmatic, neophyllic (inquisitive) omnivore that, when feral, can range over large areas $\left(28.5 \mathrm{~km}^{2}\right)$. Research on carnivores shows that those with large ranges tend to fare worse in captivity (Clubb and Mason, 2003; Hubrecht et al., 1992). Minimum space allowances set down in codes of practice or legislation tend to be relatively small (Tab. 4), therefore, it may be difficult to provide kenneling in a research environment that meets the dog's needs in total.

Even in the largest of these $\left(4.5 \mathrm{~m}^{2}\right)$ some dogs develop behavioral abnormalities. What is put into the space in terms of enrichment, etc., may well be more important than a few square centimeters of space; however smaller spaces provide fewer opportunities to provide enrichment, complexity and control for the dog.

Outdoor runs may be beneficial in providing greater complexity and interest (Hubrecht, 1993; Spangenberg et al., 2006). Dogs should be housed in socially harmonious pairs or groups and additional human socialization should be provided as it has been shown that petting lowers blood cortisol (Hennessy et al., 1998; Tuber et al., 1996). Social isolation should be avoided. Environmental enrichment is crucial (Hubrecht, 1995) and enrichment items should be provided and presented in a way as to maintain interest and activity to avoid frustration and boredom (Pullen et al., 2010). The effects of enrichment should be closely monitored. Chewing is an important behavior and items should be provided to meet this need. Social enrichment (both dog-dog and dog-human) and adequate physical and mental stimulation are also crucial, therefore exercise periods should be provided ideally on a daily basis. Noise levels can be a problem, but can be reduced by facilities that meet the animal's needs and by suitable building design. Dogs should never be debarked.

Stereotypies are an indicator that there is a welfare issue (Clubb and Mason, 2003) and the aim should be to avoid their occurrence rather than dealing with them once they have appeared. Behavior of dogs should be monitored in order to detect behavioral abnormalities and other signs of poor welfare. Indicators of acute and chronic stress are summarized in Table 5 as published in Beerda et al. (1997, 1998, 1999a,b).

If dogs do develop behavioral abnormalities, housing and husbandry practices should be examined and changed so that such behaviors are eliminated.

To improve the welfare of dogs used in biomedical research and testing, more research is needed. Observational studies to understand responses to changes in husbandry via preference and choice tests plus motivational demand studies to understand the cognitive state may be useful. The dog's olfactory sense is $10^{3}-10^{8}$ times more sensitive than ours, but there have been relatively few studies on olfactory enrichment (Graham et al., 2005) or on auditory enrichment (Wells et al., 2002).

Dogs' vision is good (Neitz et al., 1989), and kennels with clear sight lines out of the dog's enclosure are beneficial in 
providing them with the ability to predict events and exert a degree of control. Windows can be useful in providing such sightlines, and structures, such as platforms, provide additional complexity.

Other areas for future research identified by the Joint Working Group were:

- The relationship between welfare and the physical and social environment

- Economical and practical ways of enriching the kennel

- The relationship between pen size, number of individuals and behavior

- Ways to prevent and manage aggression

- The demand for different toys and chews

- The influence of early experience on behavior in laboratory Beagles

- The psychological and physiological effects of transport

As for many species, many indicators of welfare can be taken (behavioral, physiological) but these still have to be interpreted and this can be difficult. When making so-called improvements care has to be taken to ensure that real welfare improvements have been made.

There are various national and international standards that provide minimum standards for dog housing. In Europe there is the Council of Europe Convention ETS 123 and European Community Directive 2010/63/EU, which will be enacted on January 1, 2013, and more internationally there are the Organization for Economic Co-operation and Development (OECD),

Tab. 4: Comparison of minimum space allowances for medium sized dogs

\begin{tabular}{|l|c|c|}
\hline Minimum space allowance by guidelines & $\mathbf{m}^{\mathbf{2}}$ & feet $^{2}$ \\
\hline 1996 NRC Guide & 1.1 & 12 \\
\hline 2011 NRC Guide & 1.1 & 12 \\
\hline 1986 UK (1 or 2 animals) & 4.5 & 48.4 \\
\hline 2010 EU (1 or 2 animals) & 4.0 & 43.1 \\
\hline
\end{tabular}

the International Conference on Harmonization of Technical Requirements for Registration of Pharmaceuticals for Human Use $(\mathrm{ICH})$, the International Cooperation on Harmonization of Technical Requirements for Registration of Veterinary Medicinal Products $(\mathrm{VICH})$ and the World Health Organization (WHO).

AAALAC (Association for Assessment and Accreditation of Laboratory Animal Care International), is an international organization which promotes animal welfare through an accreditation program. AAALAC grants accreditation if the applicant meets or exceeds the standards set forth by the three following references plus additional reference documents:

1. " 8 th Edition of the Guide for the Care and Use of Laboratory Animals", NRC (2011);

2. "Guide for the Care and Use of Agricultural Animals in Research and Teaching" (Ag Guide), FASS (2010);

3. "European Convention for the Protection of Vertebrate Animals Used for Experimental and Other Scientific Purposes", Council of Europe (ETS 123).

AAALAC's international accreditation program is carried out mainly by independent experts, who actively visit sites, provide advice and recommendations, and award accreditation. Professional and continuous improvement of the animal care and use program, based on re-visits occurring every three years for continued accreditation, helps to raise animal welfare standards in daily practice. A retrospective analysis of AAALAC site visits in Europe from 2003 to 2008 revealed that most frequently the areas that needed improvement before accreditation could be granted were in the animal environment and veterinary care, and within these areas the subcategories "behavioral management, structural and social environment" and "preventive medicine, surveillance, diagnosis" were most prominent. Institutions that apply for accreditation have to submit a program description which typically has a volume of 100 pages or more, and host the site visitors who perform an in-depth review of the animal care and use program. Currently there are over 60 AAALACaccredited European institutions, the majority pharmaceutical

Tab. 5: Stress indicators in dogs

\begin{tabular}{|c|c|}
\hline Indicators of acute stress & Indicators of chronic stress \\
\hline Low posture & Low posture \\
\hline Body shaking & Increased autogrooming \\
\hline Crouching & Paw lifting \\
\hline Oral behaviors (tongue out, licking muzzle, swallowing) & Vocalizing \\
\hline Restlessness & Repetitive behavior \\
\hline Yawning & Coprophagy \\
\hline Heart rate change & high cortisol/creatinine ratio \\
\hline Increased cortisol/creatinine ratio & increased catecholamines \\
\hline Peripheral leukocytosis & $\begin{array}{l}\text { When stimulated: } \\
\text { High levels of locomotor activity } \\
\text { Increased levels of change of active state } \\
\text { Body shaking } \\
\text { Yawning } \\
\text { Ambivalent postures } \\
\text { Displacement behavior }\end{array}$ \\
\hline
\end{tabular}


companies and contract research organizations (CROs), though also academic and other institutions, participate in the accreditation program. In selecting a CRO, AAALAC-accreditation is an important quality marker for animal welfare.

\section{Discussion and suggestions}

As the workshop participants had backgrounds from pharmaceutical and pesticide industries, CROs, the regulatory arena, animal welfare organizations and academia, different views and experiences were brought into the discussion, and some opinions were controversial. Nevertheless, trying to find a way toward consensus gave rise to many ideas, which are summarized here. Each individual participant does not necessarily back each idea.

It was agreed that this workshop is evidence that industry and animal welfare groups can work together towards achieving best practices and furthering the 3 Rs concept. This depends on building trust and confidence, which are considered essential if ideas and data are to be shared. The power of a consortium consisting of various groups from different backgrounds to influence legislation and regulators is synergistic, and the value of sharing information is priceless. This is the way considered best to affect a change in ensuring harmonized best practice and animal welfare issues in the future.

Unfortunately, methods to fully replace the use of dogs and other animals are not available yet for some areas of research and safety testing. It is therefore obviously desirable to develop replacement methods and meanwhile reduce the numbers of dogs used in experiments. It is not more ethical to substitute dogs with another equally sentient species, e.g., mini-pigs. Therefore, an important task is to further reduce dog use and optimize laboratory conditions by refinement approaches. In order to further the refinement of work with laboratory dogs and other animals, CAAT announced the creation of an Industry Refinement Working Group and preparatory discussions so far include twelve companies. A grant from the Klingenstein Foundation allows CAAT to serve as the secretariat for this initiative, which may help to give the suggestions and recommendations from this workshop a direct impact and follow-up.

\subsection{Replacement}

The Replacement of experiments on animals, including dogs, is the final goal in both research and testing. Therefore, a key point of action will be the identification and development of suitable Replacement methods from areas like computer modeling techniques, in vitro methods, cell culture and tissue engineering that will also be fit for international acceptance and could be integrated in testing strategies, test guidelines and data requirements or that can be widely used in biomedical research. Extensive funding will be needed and should be made available. Data-bases should be created using a weight of evidence approach that also includes a cost-benefit analysis and ethical reviews.

Furthermore, a working group should be formed to identify more opportunities to conduct retrospective studies, in order to determine the initial value of the experiment, the read-out, and the practical benefit for humans. The point was made that closer analysis of what results are actually used for regulatory decisions can guide to develop selective assays. As an example (not involving dogs), a retrospective analysis of reproductive toxicity studies was mentioned, where the outcome showed, that in $80 \%$ of the cases testis toxicity was the reason for classification (Bremer et al., 2007). This is already assessed in general toxicity repeat-dose studies and is easier to model in vitro than the whole reproductive cycle. Another retrospective study on neurovirulence testing in monkeys showed that the test was unable to discriminate between the attenuated, safe vaccine virus and virulent wild type strains and was therefore banned (IABS, 2005).

A suggestion from the animal welfare side was to use the "blank paper" approach: given the assumption that no suitable test exists and toxicity studies would be developed de novo without historical prejudices, using newest technologies, and taking into account the state-of-the-art knowledge without considering existing liability issues or regulatory requirements. Such an activity would require an intense literature research for evidencebased information, including data from pharmaceutical industry, and might lead to a whole new set of in vitro approaches.

\subsection{Reduction}

In the area of reduction clear statements were made, mainly by the pharmaceutical industry based on their experience, which every experimenter, study director or managing team should follow. A guidance document might be useful that includes the following points:

- Plan properly and upon demand (most drugs do not make it into clinical trials).

- Avoid in vivo screening and parallel testing as much as possible, which requires the management to be on board.

- Choose species case-by-case, not based on preceding choice, costs or availability.

- Mini-optimize early studies ( 1 sex, $\mathrm{N}=1 /$ sex; short).

- Use fewer animals per project by combining studies and using interim sampling or biopsies.

- Avoid control animals whenever possible (e.g., in reversibility group).

- Challenge the need for reversibility data in studies, as reversibility does not distinguish adverse from non-adverse effects.

- Consider integrated approaches whenever possible, e.g., include safety pharmacology parameters in general toxicology to prevent the need for additional repeat-dose studies.

- Start at young age of animals to cover potential juvenile issues and waive stand-alone juvenile studies whenever appropriate.

- Use the animals in multiple studies, e.g., in MTD studies with insignificant toxicity.

- Think globally by performing GLP studies with globally acceptable design in order to prevent any need for repetition.

- Exchange data within industry, e.g., experience with species selection, excipients and findings irrelevant to humans ("false positive compounds").

- Use state-of-the-art methods to gain as much valuable data as possible with a minimum of stress, e.g., wireless data collection systems. 
- Publish and educate.

- Share control groups for parallel running studies, encourage CROs to do so as well. Sponsors can easily share control data.

- Do not try to save money by outsourcing into uncontrollable environments.

Summarizing the above mentioned points and developing a best practice guidance document would be a starting point for the above mentioned Industry Refinement Working Group.

\subsection{Refinement of husbandry and care taking}

Given the existing knowledge and an international accreditation body some improvements in the area of refinement already have been achieved but the main question remains: How should we define animal welfare, what should be the minimum standards, and how can we successfully measure applied animal welfare?

It was agreed that more information is needed and observational studies assessing laboratory animals in general should be carried out, taking into consideration the different stages of their life, starting with the breeding conditions, their socialization, needs when kept in stock, and their behavior under experimental conditions leading to an "Animal Welfare best practice document". This study should include state-of-the-art approaches such as monitoring by video-surveillance, and offering the animal preferences to understand what it really needs.

This can be done by a step-by-step or a gap analysis but should definitely lead to an evidence-based refinement approach. The creation of an animal welfare score, similar to the trauma score assessed in emergency settings in hospitals, was suggested. The animal welfare score could be like a checklist of different measures, with the distinct purpose of leading to a profile of a balanced or at least un-distressed animal when following the minimum recommendations.

\subsection{Refinement of procedures}

The workshop participants also identified a need to take action regarding the severity of procedures. As discussed before, no publicly available data describes commonly used procedures. A study should be financed and conducted to identify severe procedures as defined in the severity classification in Annex VIII of Directive 2010/63/EU ${ }^{14}$ and experts should confer to make recommendations that would lessen their severity.

Humane endpoints need to be better defined; especially the termination criteria in the maximum tolerated dose study, which can inflict a severe level of distress and pain. Working groups currently exist, e.g., EFPIA/NC3Rs acute toxicity project, which could be encouraged to address this topic, taking into consideration the OECD Guidance Document $19^{15}$ on the recognition, assessment and use of clinical signs as humane endpoints for experimental animals used in safety evaluation.

The use of non-invasive methodologies, like PET scan imaging, as well as interim sampling, biomarker studies, biopsies instead of killing, are preferred.

Well-trained, empathetic staff is one of the most important assets for animal welfare; therefore, training procedures are criti- cal and there should be a minimum requirement for educational training as well as assessment of the competence of animal caretakers, experimenters and their trainers, as described in the new Directive 2010/63/EU.

An area where information is still needed, and which could be addressed by additional workshops, is the requirement for juvenile testing, because this may create a whole new point of view on the need of animal testing.

\subsection{Regulatory acceptance and globalization}

Regulatory acceptance and globalization are major factors to take into account. As long as one market requests a certain study, this type of test still will be carried out as seen in the case of the one year study for pesticides, which has been abandoned by the EU and US, but is still required in Brazil and Japan. A formal meeting with regulators from different countries is being discussed by CAAT-US, at which existing data can be presented and decisions to adopt international standards can be discussed.

Harmonization of minimum standards and data requirements and adaptation to scientific and technical progress at a national and international level is considered essential. This should be done in Europe through the European Commission and more internationally through the respective organizations, like the OECD, the ICH and the VICH.

Furthermore it was recognized that regulatory authorities are starting to be more confident in the quality of non-clinical data and more flexible in considering non-standard approaches. New experimental models including the use of novel tools are now more readily accepted by regulatory authorities.

\section{Recommendations}

\section{Increase knowledge}

1. Observational studies to understand natural and kenneled behavior of dogs using preference and choice tests taking into consideration the different stages of their life

2. Identification of the possibilities for retrospective studies, to determine the initial value of the experiment, the read-out and the practical benefit for the human

3. Given the lack of data assessing the predictive power from dog to humans for a large number of drugs or drug candidates, a large retrospective analysis should be carried out

4. Individual identification of severe procedures performed with laboratory animals with the goal to change them into mild procedures

\section{Guidance documents}

1. Replacement guidance document

2. Reduction guidance document

3. "Animal Welfare best practice document" achieved by an evidence-based approach creating an animal welfare score or indicator

\footnotetext{
14 http://eur-lex.europa.eu/LexUriServ/LexUriServ.do?uri=OJ:L:2010:276:0033:0079:En:PDF

$15 \mathrm{http}: / /$ www.imm.ki.se/stt/pdf/OECD19.pdf
} 
4. Minimum requirement for educational training and the ability to assess the competence of animal caretakers, experimenters and their trainers

5. Species selection guidance (currently under revision by EFPIA)

\section{Online databases}

1. Data sharing within the pesticide, chemical and pharmaceutical sectors

2. Extension of the existing database of animal experiments containing in vivo toxicological information on e.g., vehicles, solvents, excipients, preservatives, procedures, species and selected chemicals including also a cost benefit analysis and ethical reviews

\section{Workshops and meetings}

1. Juvenile testing requirement especially for dogs

2. Meetings for regulators to enhance global harmonization

\section{References}

Alon, U., (2007). Network motifs: theory and experimental approaches. Nat. Rev. Genet. 8, 450-461.

Andersen, M. E., Clewell, H. J., Carmichael, P. L. and Boekelheide, K. (2011). Can case study approaches speed implementation of the NRC report: "Toxicity Testing in the $21^{\text {st }}$ Century: A Vision and a Strategy?" ALTEX 28, 175-182.

Beerda, B., Schilder, M., Van Hooff, J., et al. (1997). Manifestations of chronic and acute stress in dogs. Appl. Anim. Behav. Sci. 52, 307-319.

Beerda, B., Schilder, M., Van Hooff, J., et al. (1998). Behavioral, saliva cortisol and heart rate responses to different types of stimuli in dogs. Appl. Anim. Behav. Sci. 58, 365-381.

Beerda, B., Schilder, M., Van Hooff, J., et al. (1999a). Chronic stress in dogs subjected to social and spatial restriction. I. Behavioral responses. Physiol. Behav. 66, 233-242.

Beerda, B., Schilder, M., Van Hooff, J., et al. (1999b). Chronic stress in dogs subjected to social and spatial restriction. II. Hormonal and immunological responses. Physiol. Behav. 66, 243-254.

Bremer, S., Pellizzer, C., Hoffmann, S., et al. (2007). The development of new concepts for assessing reproductive toxicity applicable to large scale toxicological programs. Curr. Pharm. Des. 13, 3047-3058.

Broadhead, C., Betton, G., Combes R., et al. (2000). Prospects for reducing and refining the use of dogs in the regulatory toxicity testing of pharmaceuticals. Hum. Exp. Toxicol. 19, 440-447

Box, R. J. and Spielmann, H. (2005). Use of the dog as nonrodent test species in the safety testing schedule associated with the registration of crop and plant protection products (pesticides): present status. Arch. Toxicol. 79, 615-626.

BVAAWF/FRAME/RSPCA/UFAW Joint Working Group on Refinement. (2004). Refining dog husbandry and care. Eighth report of BVAAWF/FRAME/RSPCA/UFAW Joint Working Group on Refinement. Lab. Anim. 38 Suppl, 1-94.

Clubb, R. and Mason, G. (2003). Captivity effects on wideranging carnivores. Nature 425, 473-474.
Dellarco, V. L., Rowland, J., and May, B. (2010). A retrospective analysis of toxicity studies in dogs and impact on the chronic reference dose for conventional pesticide chemicals. Crit. Rev. Toxicol. 40, 16-23.

Derr, M. (2004). Dog's best friend. Vol. 2. Chicago: University of Chicago Press.

Dewey, T. and Bhagat, S. (2002). Canis lupus familiaris (Online). Animal Diversity Web.

Du Sert, N. P., Holmes, A. M., Wallis. R., et al. (2011). Predicting the emetic liability of novel chemical entities: a comparative study. Br. J. Pharmacol., Epub ahead of print.

Forster, R., Bode, G., Ellegaard, L., et al. (2010). The RETHINK project: Minipigs as models for the toxicity testing of new medicines and chemicals: an impact assessment. $J$. Pharmacol. Toxicol. Methods 62, 158-159.

Franklin, A. (2006). Be[a]ware of the dog: a post-humanist approach to housing. Housing, Theory and Society 23, 137-156.

Gácsi, M., Gyori, B., Miklósi, A., et al. (2005). Species-specific differences and similarities in the behavior of hand-raised dog and wolf pups in social situations with humans. Dev. Psychbiol. 47, 111-122.

Gerbracht, U. and Spielmann, H. (1998). The use of dogs as second species in regulatory testing of pesticides. I. Interspecies comparison. Arch. Toxicol. 72, 319-329.

Graham, L., Wells, D., and Hepper, P. (2005). The influence of olfactory stimulation on the behavior of dogs housed in a rescue shelter. Appl. Anim. Behav. Sci. 91, 143-153.

Hartung, T. (2008a). Food for thought ... on animal tests. ALTEX 25, 3-16.

Hartung, T. (2008b). Food for thought ... on alternative methods for cosmetics safety testing. ALTEX 25, 147-162.

Hartung, T. and Koëter, H. (2008). Food for thought ... on food safety testing. ALTEX 25, 259-264.

Hartung, T. and Leist, M. (2008). Food for thought ... on the evolution of toxicology and the phasing out of animal testing. ALTEX 25, 91-102.

Hartung, T. (2009a). Toxicology for the twenty-first century. Nature 460, 208-212.

Hartung, T. (2009b). Food for thought ... on evidence-based toxicology. ALTEX 26, 75-82.

Hartung, T. (2010a). Comparative analysis of the revised Directive 2010/63/EU for the protection of laboratory animals with its predecessor 86/609/EEC - a t ${ }^{4}$ report. ALTEX 27, 285-303.

Hartung, T. (2010b). Evidence-based toxicology - the toolbox of validation for the $21^{\text {st }}$ century? ALTEX 27, 253-263.

Hartung, T. (2011). From alternative methods to a new toxicology. Eur. J. Pharm. Biopharm. 77, 338-349.

Hartung, T. and McBride, M. (2011). Food for thought ... on mapping the human toxome. ALTEX 28, 83-93.

Headey, B. (1999). Health benefits and health cost savings due to pets: preliminary estimates from an Australian national survey. Soc. Indic. Res. 47, 233-243.

Hejjas, K., Vas, J., Topal, J., et al. (2007). Association of polymorphisms in the dopamine D4 receptor gene and the activity-impulsivity endophenotype in dogs. Anim. Genet. 38, 629-633. 
Hennessy, M., Williams, M., Miller, D., et al. (1998). Influence of male and female petters on plasma cortisol and behavior: Can human interaction reduce the stress of dogs in a public animal shelter? Appl. Anim. Behav. Sci. 61, 63-77.

Hoffmann, S. and Hartung, T. (2006). Toward an evidencebased toxicology. Hum. Exp. Toxicol. 25, 497-513.

Hubrecht, R., Serpell, J., and Poole, T. (1992). Correlates of pen size and housing conditions on the behaviour of kennelled dogs. Appl. Anim. Behav. Sci. 34, 365-383.

Hubrecht, R. (1993). A comparison of social and environmental enrichment methods for laboratory housed dogs. Appl. Anim. Behav. Sci. 34, 365-383.

Hubrecht, R. (1995). Enrichment in puppyhood and its effects on later behavior of dogs. Lab. Anim. Sci . 45, 70-75.

Hubrecht, R. and Kirkwood, J. (2010). The UFAW handbook on the care and management of laboratory and other research animals. $8^{\text {th }}$ edition. Oxford: Wiley-Blackwell.

IABS (2005). Scientific workshop on neurovirulence tests for live virus vaccines. WHO

Jaworska, J. and Hoffmann, S. (2010). Integrated testing Strategy (ItS) - Opportunities to better use existing data and guide future testing in toxicology. ALTEX 27, 231-242.

Karlsson, E. and Lindblad-Toh, K. (2008). Leader of the pack: gene mapping in dogs and other model organisms. Nat. Genet. Rev. 9, 713-725.

Kim, J. and Scialli, A. (2011). Thalidomide: the tragedy of birth defects and the effective treatment of disease. Tox. Sci. 122, 1-6. Kobel, W., Fegert, I., Billington, R., et al. (2010). A 1-year toxicity study in dogs is no longer a scientifically justifiable core data requirement for the safety assessment of pesticides. Crit. Rev. Toxicol. 40, 1-15.

Kobel, W., Fegert, I., Billington, R., et al. (2010). A 1-year toxicity study in dogs is no longer a scientifically justifiable coredata requirement for the safety assessment of pesticides. Crit. Rev. Toxicol. 40, 1-15.

Krewski, D., Acosta, D., Andersen, M., et al. (2010). Toxicity testing in the 21st century: A vision and a strategy. J. Toxicol. Environ. Health B Crit. Rev. 13, 51-138.

Kuegler, P., Zimmer, B., Waldmann, T., et al. (2010). Markers of murine embryonic and neural stem cells, neurons and astrocytes: reference points for developmental neurotoxicity testing. ALTEX 27, 17-42.

Leist, M., Bremer, S., Brundin, P., et al. (2008). The biological and ethical basis of the use of human embryonic stem cells for in vitro test systems or cell therapy. ALTEX 25, 163-190.

Matthews, R. (2008). Medical progress depends on animal models - doesn't it? J. R. Soc. Med. 101, 95-98.

Miklósi, Á. (2007). Dog, behavior, evolution, and cognition. Vol. 1. Oxford: Oxford University Press

Neitz, J., Geist, T., and Jacobs, G. (1989). Color vision in the dog. Visual Neuroscience 3, 119-125.

NRC (2007). Toxicity testing in the $21^{\text {st }}$ century: A vision and a strategy. Washington, DC: the National Academies Press.

Olson, H., Betton, G., Robinson, D., et al. (2000). Concordance of the toxicity of pharmaceuticals in humans and in animals. Reg. Tox. Pharm. 32, 56-67.
Pan, Y., Larson, B., Araujo, J., et al. (2010). Dietary supplementation with medium-chain TAG has long-lasting cognitionenhancing effects in aged dogs. Br. J. Nutr. 103, 1746-1754.

Podberscek, A. (2006). Positive and negative aspects of our relationship with companion animals. Vet. Res. Commun. 30, 21-27.

Power, E. (2008). Furry families: Making a human-dog family through home. Soc. Cult. Geogr. 9, 535-555.

Pullen, A., Merrill, R., and Bradshaw, J. (2010). Preferences for toy types and presentations in kennel housed dogs. Appl. Anim. Behav. Sci. 125, 151-156.

Russell, W. and Burch, R. (1959). The principles of humane experimental technique. Herts, UK: Universities Federation for Animal Welfare (UFAW).

Smith, D., Broadhead, C., Descotes, G., et al. (2002). Preclinical safety evaluation using non-rodent species: An industry/ welfare project to minimize dog use. ILAR 43, 39-42

Smith, D., Combes, R., Depelchin, O., et al. (2005). Optimizing the design of preliminary toxicity studies for pharmaceutical safety testing in the dog.Regul.Toxicol.Pharmacol.41,95-101. Smith, D., Combes, R., Delaunois, A., et al. (2007). Minimization of dog use in safety assessment of pharmaceuticals. Progress with the EFPIA/RSPCA/FRAME project. Toxicology 231, 97-98.

Spangenberg, E., Björklund, L., and Dahlborn, K. (2006). Outdoor housing of laboratory dogs: Effects on activity, behavior and physiology. Appl. Anim. Behav. Sci. 98, 260-276.

Spielmann, H. and Gerbracht, U. (2001). The use of dogs as second species in regulatory testing of pesticides. Part II: Subacute, subchronic and chronic studies in the dog. Arch. Toxicol. 75, 1-21.

Tuber, D., Hennessy, M., Sanders, S., et al. (1996). Behavioral and glucocorticoid responses of adult domestic dogs (Canis familiaris) to companionship and social separation. J. Comp. Psychol. 110, 103-108.

Wells, D., Graham, L., and Hepper, P. (2002). The influence of auditory stimulation on the behaviour of dogs housed in a rescue shelter. Anim. Welfare 11, 385-393.

Wells, D. (2004). A review of environmental enrichment for kennelled dogs, Canis familiaris. Appl. Anim. Behav. Sci. 85, 307-317.

\section{Acknowledgement}

The authors wish to thank the Doerenkamp-Zbinden Foundation for sponsoring this workshop as part of the $t^{4}$ activities.

\section{Correspondence to}

Thomas Hartung, MD PhD

Johns Hopkins Center for Alternatives to Animal testing 615 North Wolfe Street

W7032, Baltimore

MD 21205, USA

e-mail: thartung@jhsph.edu 